\title{
Effect of Maleated Polyethylene on the Rheological Properties of LLDPE/Clay Nanocomposites
}

\author{
Youn Cheol KIM,,${ }^{1,}$ Sang Jin LEE, ${ }^{2}$ Jin Chul KIM, ${ }^{3}$ and Hansol $\mathrm{CHO}^{4}$ \\ ${ }^{1}$ Department of Advanced Materials Chemical Technology, Cheonan National Technical College, \\ 175, Budae-Dong, Cheonan 330-717, Korea \\ ${ }^{2}$ Department of Advanced Materials Science and Engineering, Mokpo National University, Muan 534-729, Korea \\ ${ }^{3}$ School of Biotechnology \& Bioengineering, Kangwon National University, \\ 192-1, Hyoja2-dong, Chunchon, Kangwon-do 200-701, Korea \\ ${ }^{4}$ Flexible Display Program Team, Materials and Devices Research Center, Samsung Advanced Institute of Technology, \\ Mt. 14-1, Nongseo-ri, Giheung-eup, Yongin-si, Gyeonggi-do 449-712, Korea
}

(Received September 17, 2004; Accepted November 25, 2004; Published March 15, 2005)

\begin{abstract}
Linear low density polyethylene (LLDPE)/20A composites were prepared by adding a moderate amount of maleic anhydride grafted polyethylene (MA- $g$-PE). The dispersion of the modified montmorillonite (20A) in LLDPE matrix depended on the amount of MA- $g$-PE. When the content of MA- $g$-PE was higher than $15 \mathrm{wt} \%$, the exfoliated nanocomposite was obtained. The nanocomposites of adding a MA- $g$-PE showed unusual rheological properties such as high shear thinning tendency and elastic property. These effects were confirmed by an oscillatory viscometer. The wavy melt fracture occurred at $8720 \mathrm{~s}^{-1}$ for the LLDPE/20A composite but occurred at $10500 \mathrm{~s}^{-1}$ for LLDPE/20A composites containing $15 \mathrm{wt} \%$ MA- $g$-PE. The MA- $g$-PE modified LLDPE/clay composite could be less sensitive to melt fracture because the composite has a high elastic property to resist elongational stress when leaving the die. [DOI 10.1295/polymj.37.206]

KEY WORDS Maleic Anhydride / Linear Low Density Polyethylene / Nanocomposite / Rheological Property / Melt Fracture /
\end{abstract}

Polymer composite has been prepared by mechanical blending of polymer matrix and glass fiber or other inorganic materials to reinforce unfilled polymer. In these conventional composites, the additives are not homogeneously dispersed in the polymer matrices at the microscopic level. If the reinforcement of fillers can be achieved at the microscopic level, the physical properties would be further improved. There is much interest, scientifically and technologically, in nanocomposites of polymers with nanoscale layered silicates because these materials offer markedly improved properties as compared to the conventional polymer composites. ${ }^{1-8}$ Further, these improvements are achieved at very low loadings of the inorganic component.

Another field of interest with the polymer nanocomposite was that the melts possess unusual viscoelastic properties such as non-terminal dynamic moduli at low frequency and a high shear thinning tendency. ${ }^{9,10}$ The rheology of polymer nanocomposites was not affected by the chemical nature of the polymer but rather by the mesoscopic structure of the hybrid. The clay tactoids form a percolating network as a result of physical jamming, which then offers considerable resistance to deformation and hence the solid-like behavior. ${ }^{9}$ Large amplitude dynamic da- ta showed a decrease in the storage modulus and it was postulated that flow-induced alignment of the clay occurs at higher strain. It is well-known that flow-induced alignment can alter the rheological properties in their molten state. ${ }^{9,11-13}$

Linear low density polyethylene (LLDPE) is extensively used in plastic markets using extrusion process such as films, electrical insulation material, and so on. ${ }^{14,15}$ Of these applications, power cables especially require insulation material that exhibits good surface roughness. There are several causes for surface roughness in extrusion process. An irregular dimensional change in the molten polymer is the main cause of the melt fracture after it exits the die in the extrusion process. Some researchers reported that the dimensional change is due to a low elastic property and shear sensitivity of the melt to the flow fields it encounters. ${ }^{16,17}$ Linear polyethylene nanocomposite by adding small amount clay is becoming accepted as new method of altering rheological properties, such as a change in elastic property and shear sensitivity. ${ }^{9}$ This is the reason that the study of the LLDPE nanocomosite on the rheological behavior is a topic of interest.

Since LLDPE does not include any polar group in its backbone, it is thought that the homogeneous dis-

${ }^{\dagger}$ To whom correspondence should be addressed (E-mail: younkim@cntc.ac.kr). 
persion of the clay minerals in polyethylene is not realized. In general, the clay is modified with alkylammonium to facilitate its interaction with a polymer because the alkylammonium make the hydrophilic clay surface organophilic. However, the organically modified clay does not disperse well in the nonpolar polypropylene or polyethylene since such non-polar polymers are still too hydrophobic. ${ }^{18,19}$

Initial attempts to create the nonpolar polymer/clay nanocomposites by simple melt mixing were based on the introduction of a modified oligomer to mediate the polarity between the clay surface and polymer. ${ }^{20-23}$ One of the typical examples is MA-g-PE/clay nanocomposites system. ${ }^{22,23}$ Although there have been considerable studies on the physical properties of the polyolefin nanocomposites, little progress has been made in the effect of MA- $g$-PE content on the rheological property and surface roughness of LLDPE/ clay nanocomposite.

The present study was carried out to determine the effects of MA- $g$-PE content on rheological properties and surface roughness in extrusion process. LLDPE/ clay nanocomposites containing MA- $g$-PE was accomplished with a laboratory-scale melt mixer and a systematic study was made on the effects of MA- $g$ PE concentrations.

\section{EXPERIMENTAL}

\section{Materials}

Polyethylene used in this study was LLDPE from Samsung General Chemicals of Korea with a melt in$\operatorname{dex}=2.4 \mathrm{~g} / 10 \mathrm{~min}\left(190^{\circ} \mathrm{C}, 2.16 \mathrm{~kg}\right)$ and a density $=$ $0.923 \mathrm{~g} \mathrm{~cm}^{-3}$.

The modified montmorillonite (Closite 20A, abbreviation: 20A) supplied by Southern Clay Products was used, which was ion-exchanged with dimethyl dihydrogenate tallow ammonium ions. (Tallow was composed pre-dominantly of octadecyl chains with smaller amount of lower homologues. The approximate composition was $\mathrm{C}_{18} 65 \%, \mathrm{C}_{16} 30 \%$ and $\mathrm{C}_{14} 5 \%$.)

Maleic anhydride modified polyethylene (MA- $g$ PE, $0.85 \%$ wt $\%$ maleic anhydride grafted, Aldrich) were used. All chemicals were used without further purification.

Several types of the composites with different compositions of the organically modified clays and LLDPE containing MA- $g$-PE were prepared by melt compounding at $140^{\circ} \mathrm{C}$, using Brabender mixer with the chamber size of $50 \mathrm{~cm}^{3}$. Screw speed was $60 \mathrm{rpm}$ and the mixing time was $20 \mathrm{~min}$ for all the cases.

\section{Measurements}

$\mathrm{X}$-Ray diffraction (XRD) was carried out by using Rigaku X-ray generator $(\mathrm{Cu} \mathrm{K} \alpha$ radiation with $\lambda=$
$0.15406 \mathrm{~nm})$ at room temperature. The diffractograms were scanned in $2 \theta$ ranges from 1.2 to $20^{\circ}$ at a rate of $2^{\circ} \mathrm{min}^{-1}$. Transmission electron microscope, Pillips CM20, was used to observe the dispersibility of the clay in hybrids using an acceleration voltage of $120 \mathrm{kV}$. An ultra-thin section of $70 \mathrm{~nm}$ in thickness was prepared by an ultra-microtome Leica EM FCS. Thermal properties of the composites were performed on a TA Instruments (TA50). Heating rates were fixed at $20^{\circ} \mathrm{C} \mathrm{min}^{-1}$ and all measurements were run under an atmosphere of dry nitrogen. FT-IR were used to measure the maleic anhydride (MA) grafting level to polyethylene prepared by melt extrusion. The FT-IR spectra were recorded on a Bomen-MB-100 FT-IR spectrometer with a $4 \mathrm{~cm}^{-1}$ resolution. Rheological properties was monitored using an oscillatory viscometer (Physica, Rheo-Lab MC 120) in a parallel plate type of geometry $\left(12.5 \mathrm{~mm}\right.$ in radius) at $200^{\circ} \mathrm{C}$. Disk-shaped samples were molded at $200^{\circ} \mathrm{C}$ by a laboratory hot press under about 10 metric tons and dried in a vacuum oven for $24 \mathrm{~h}$ before the test. The samples were diameter in $25 \mathrm{~mm}$ and thickness was $2 \mathrm{~mm}$. The gap between the plates was $1.2 \mathrm{~mm}$. Onset of melt fracture was determined by observation of the appearance (the surface roughness of extrudate) of extrudates made by Hakke capillary rheometer (Rheocord $90, L / D=16, D=1.2 \mathrm{~mm}$ ) at $200^{\circ} \mathrm{C}$. The surface of the extrudate was measured by Scanning Electron Microscopy (SEM, ZEOL-JSM 6300). Measured surfaces were coated with gold for the microscopy.

\section{RESULTS AND DISCUSSION}

\section{Effect of MA-g-PE on the Basic Properties of LLDPE/ Clay Composites}

LLDPE/20A composites were prepared by melt compounding, and the effect of MA- $g$-PE on the physical properties of the composite was investigated. Figure 1 shows DSC and TGA thermograms of the LLDPE/20A composites with $5 \mathrm{wt} \%$ of 20A. No MA- $g$-PE composite (PE-A5MA0) displayed a degradation temperature at about $399^{\circ} \mathrm{C}$. When MA-g-PE is loaded in LLDPE/20A, the degradation temperature of the composites increased by $30-60{ }^{\circ} \mathrm{C}$ with MA- $g$-PE concentration. Formulations and thermal properties of the composites are summarized in Table I. Figure 2 shows the FT-IR spectra of LLDPE/ 20A composites with MA- $g$-PE. It is found that new peaks appear at $1780 \mathrm{~cm}^{-1}(\mathrm{C}=\mathrm{O})$ in the composites with MA- $g$-PE compared to the composite without MA- $g$-PE. New peak indicate that MA- $g$-PE has been successfully blended in LLDPE matrix. The figure shows also the increase of peak height at $1780 \mathrm{~cm}^{-1}$ with the increase of MA- $g$-PE content. This peak increase is consistent with MA weight percentage, so 


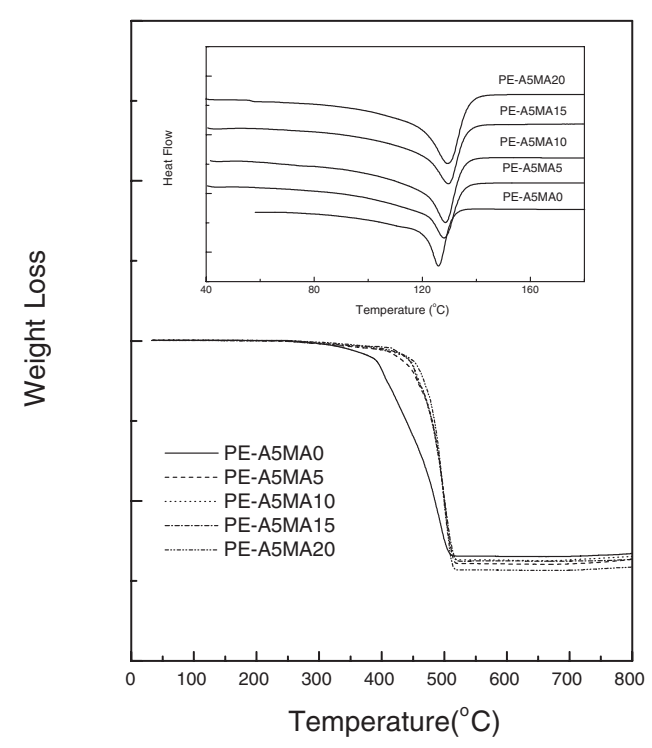

Figure 1. TGA and DSC thermograms of the LLDPE/20A composites. the MA grafting level was measured from the intensity of $1780 \mathrm{~cm}^{-1}$, and the thickness variation of each sample was corrected by $2019 \mathrm{~cm}^{-1}$ intensity for internal reference peak. ${ }^{24}$ Figure 3 shows the peak ratio of $1780 / 2019 \mathrm{~cm}^{-1}$ as a function of PE- $g$-MA content. MA weight percentages calculated by peak ratio are summarized in Table I.

Figure 4 shows the XRD curve of the LLDPE/20A composites without MA- $g$-PE. The interlayer distance is determined by the diffraction peak in the X-ray method, using the Bragg equation:

$$
2 d_{001} \sin \theta=\lambda
$$

where $d_{001}$ is the interplanar distance of (001) diffraction face, $\theta$ is the diffraction position and $\lambda$ is the wavelength. The $\mathrm{X}$-ray pattern shows clearly that the interlayer spacing decreases with the increase in content of 20A. The interlayer spacing of PEA1MA0, PE-A3MA, PE-A5MA0, PE-A7MA0, and

Table I. Formulations and thermal properties of the LLDPE/20A composites

\begin{tabular}{lccccccc} 
Materials & $\begin{array}{c}\text { LLDPE } \\
(\mathrm{wt} \%)\end{array}$ & $\begin{array}{c}\text { 20A } \\
(\mathrm{wt} \%)\end{array}$ & $\begin{array}{c}\text { MA- } g \text {-PE } \\
(\mathrm{wt} \%)\end{array}$ & $\begin{array}{c}\text { Grafted MA } \\
\text { wt } \% \\
\text { in LLDPE }\end{array}$ & $\begin{array}{c}T_{\mathrm{m}} \\
\left({ }^{\circ} \mathrm{C}\right)\end{array}$ & $\begin{array}{c}\Delta H \\
\mathrm{~J} / \mathrm{g}\end{array}$ & $\begin{array}{c}T_{\mathrm{d}}{ }^{\mathrm{b}} \\
\left({ }^{\circ} \mathrm{C}\right)\end{array}$ \\
\hline PE-A1MA0 & 99 & 1 & 0 & - & 127.1 & 63.5 & 374 \\
PE-A3MA0 & 97 & 3 & 0 & - & 125.9 & 63.4 & 388 \\
PE-A5MA0 & 95 & 5 & 0 & - & 126.0 & 58.1 & 399 \\
PE-A7MA0 & 93 & 7 & 0 & - & 126.9 & 51.5 & 400 \\
PE-A5MA5 & 90 & 5 & 5 & 0.036 & 128.2 & 53.4 & 428 \\
PE-A5MA10 & 85 & 5 & 10 & 0.088 & 128.5 & 62.3 & 441 \\
PE-A5MA15 & 80 & 5 & 15 & 0.123 & 129.6 & 59.4 & 445 \\
PE-A5MA20 & 75 & 5 & 20 & 0.164 & 129.5 & 52.0 & 457 \\
PE-A0MA15 & 85 & 0 & 15 & 0.127 & 126.1 & 63.5 & 361 \\
\hline
\end{tabular}

${ }^{\mathrm{a}}$ Calculated from FT-IR data. ${ }^{\mathrm{b}}$ Degradation temperature measured by TGA ${ }^{\mathrm{c}} T_{\mathrm{m}}, T_{\mathrm{d}}$ and $\Delta H$ of LLDPE resin are $127.4{ }^{\circ} \mathrm{C}, 370^{\circ} \mathrm{C}$ and $64.7 \mathrm{~J} / \mathrm{g}$.

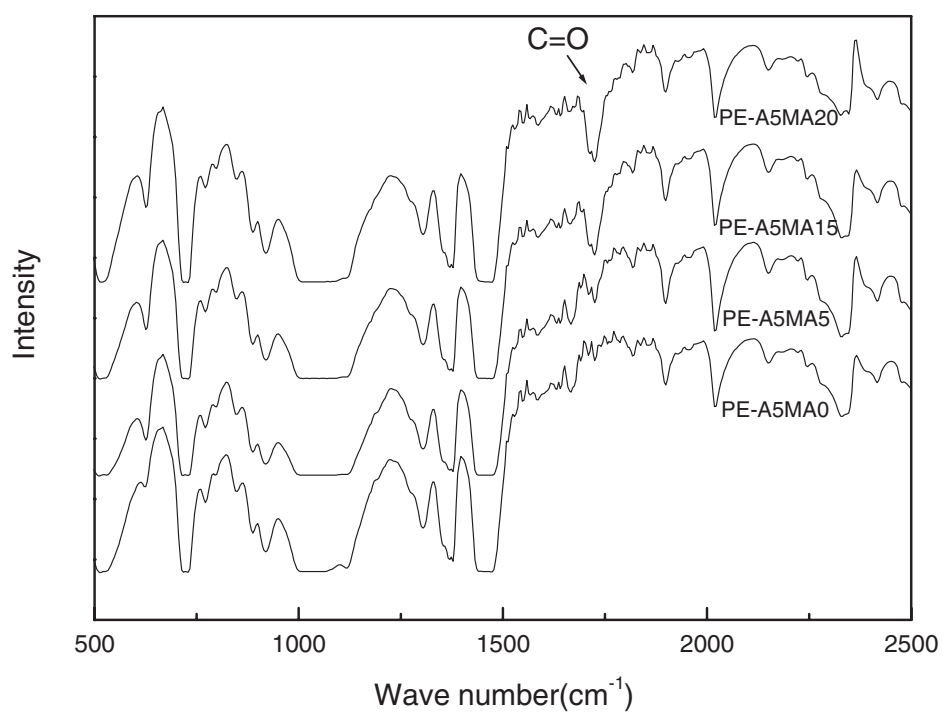

Figure 2. FT-IR spectra of the LLDPE/20A composites. 


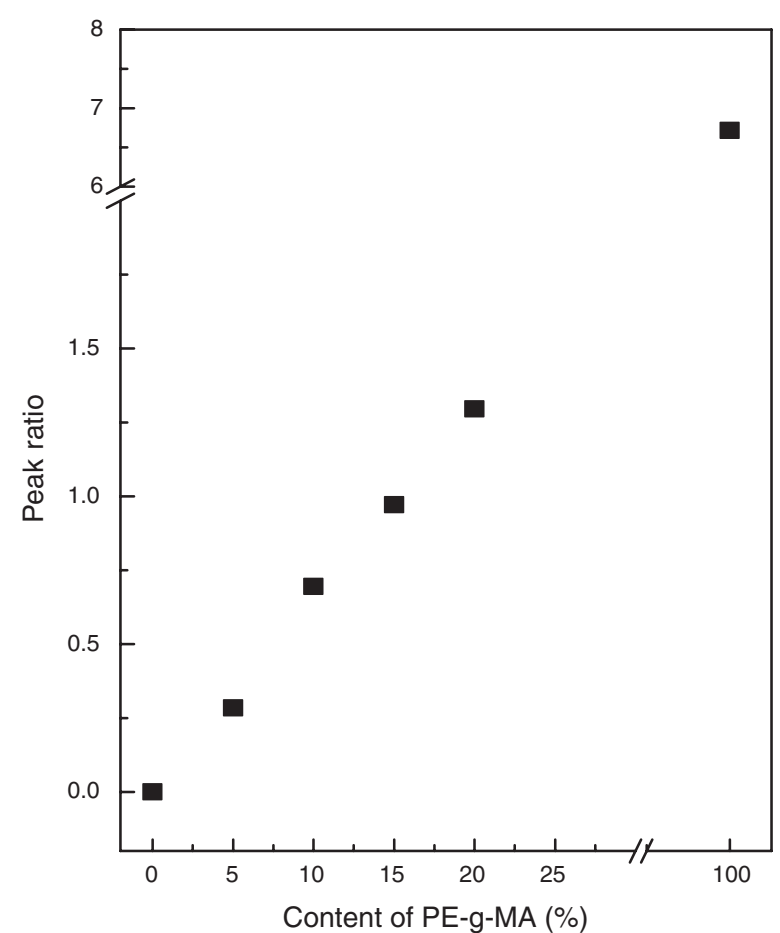

Figure 3. The peak ratio of $1780 / 2019 \mathrm{~cm}^{-1}$ as a function of the content of MA- $g$-PE.

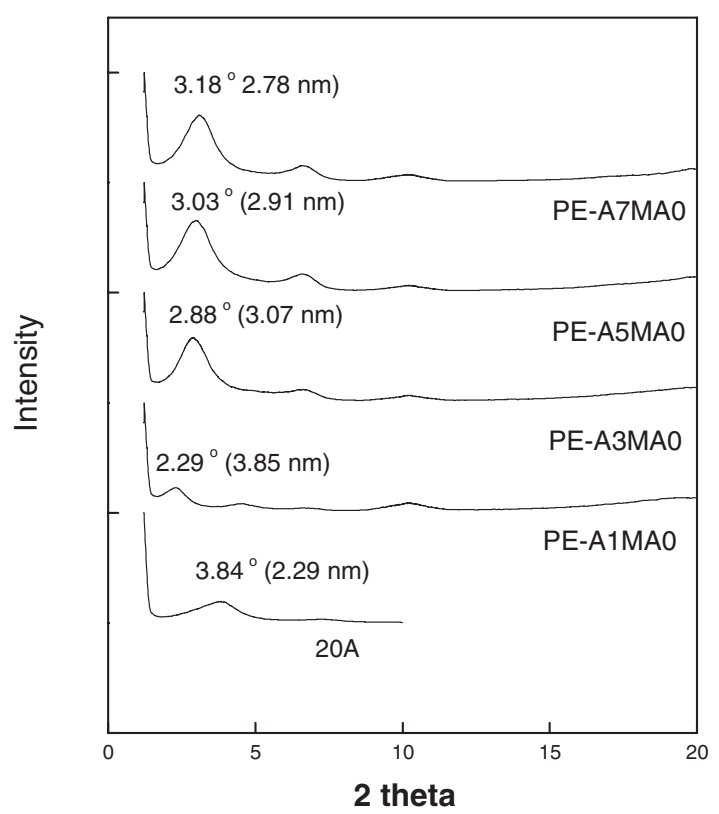

Figure 4. XRD patterns for the LLDPE/20A composites without MA- $g$-PE.

$20 \mathrm{~A}$ are $2.29,3.85,3.07,2.91$ and $2.78 \mathrm{~nm}$, respectively. The slight decrease in the interlayer spacing with the increased amount of $20 \mathrm{~A}$ is an indication of poor intercalation.

MA- $g$-PE concentration will be important thing to the 20A dispersion in LLDPE/20A composite. The effects of MA- $g$-PE on the interlayer spacing of the 20A in LLDPE matrix were investigated. The content of

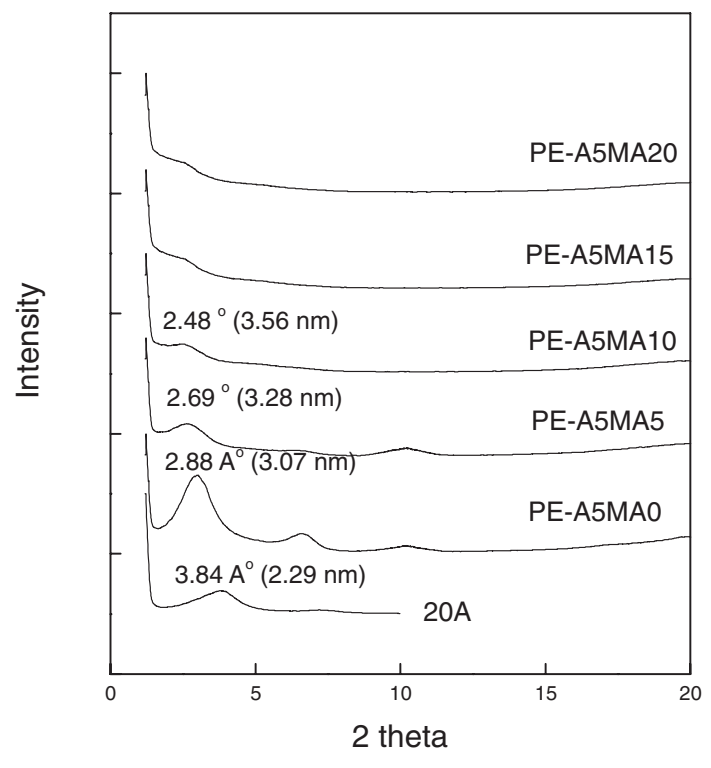

Figure 5. XRD patterns for the LLDPE/20A composites before and after loading MA- $g$-PE.

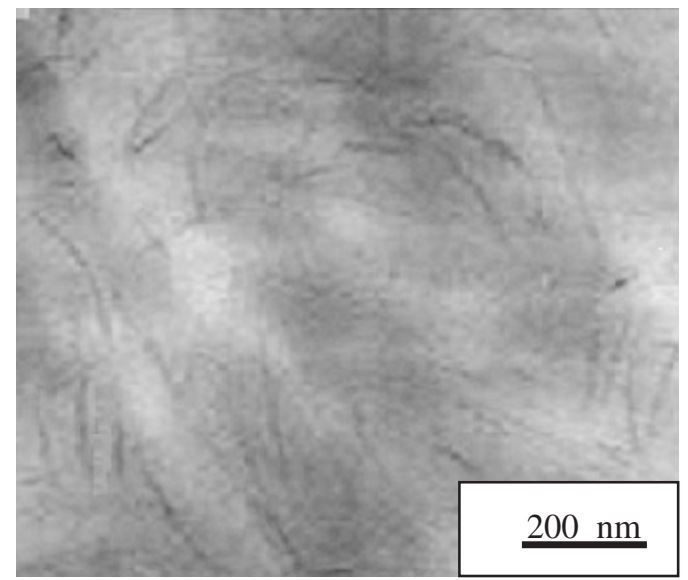

Figure 6. TEM image for the LLDPE/20A composite with $15 \%$ wt MA- $g$-PE.

the $20 \mathrm{~A}$ is fixed at $5 \mathrm{wt} \%$ in all composites. XRD patterns of the LLDPE/20A composites with MA-g-PE are shown in Figure 5. The original basal reflection peak of 20A disappears above a certain concentration of MA- $g$-PE, which is about $15 \mathrm{wt} \%$. But below this critical concentration of MA- $g$-PE, a new basal reflection peak with very weak intensity appears at lower angle than the peak of the composite without MA- $g$ PE. This fact reveals that clays are exfoliated and dispersed homogeneously in the LLDPE matrix with MA- $g$-PE. In order to confirm the nanoscale dispersion of clay, the morphology of the composite with MA- $g$-PE of $15 \mathrm{wt} \%$ was observed by transmission electron microscopy (TEM). In Figure 6, the dark lines are the clay layers. Each layer of clay is disordered and dispersed homogeneously in the composite. It is consistent with the absence of (001) plane peak in 
Figure 4 due to very large interlayer spacing and the disordered state of the clay layer. From these results, it is found that the malaeted modification is an important factor to improve the dispersion of clay in the LLDPE matrix.

\section{The Rheological Properties of LLDPE/20A Compo- sites}

The rheological properties in molten state are very sensitive to change of molecular structure such as chain branching (or molecular weight distribution), cross-linking, and network as a result of physical jamming of clay. Oscillatory measurements were used to observe the effects of the maleated modification on rheological properties of LLDPE/20A composites. The complex viscosities obtained for LLDPE/20A composites before and after loading MA- $g$-PE are shown in Figure 7. The measured temperature and strain were $200{ }^{\circ} \mathrm{C}$ and $5 \%$, respectively. All data presented in this paper was verified to be in the linear regime at $200{ }^{\circ} \mathrm{C}$ and $5 \%$ strain. The complex viscosities of the composites without MA- $g$-PE showed a monotonic increase at all frequency ranges with increasing $20 \mathrm{~A}$ concentration as shown in Figure 7a. On the other hand, there was a completely different flow pattern for the composite with MA- $g$-PE. The shear sensitivity and complex viscosity at low frequency increased with MA-g-PE concentration. The similar behaviors were observed for the silicate-based nanocomposites. ${ }^{9} 10,25,26$ The silicate layers would form network locally despite the exfoliation of a composite due to the highly anisotropic nature of the layered silicates. That is, flow-induced alignment of network in the composite results in increase in complex viscosity and shear thinning tendency. The shear sensitivity data are summarized in Table II.

To investigate the effect of the maleated modification on the rheological properties further, the plot of $\log G^{\prime}$ against $\log G^{\prime \prime}$ was made for the LLDPE/20A composites as shown in Figure 8. In case of the composites without MA- $g$-PE as shown in Figure 8a, there is no detectable change in plot of storage $\left(G^{\prime}\right) v s$. loss $\left(G^{\prime \prime}\right)$ modulus. The fact to lie on a single correlation suggests that the molecular structure in molten state is not significantly altered due to the insufficient interaction between LLDPE and 20A. However, there is a completely different pattern (shift toward left) for the composites with MA-g-PE as shown in Figure 8b. Moving toward left, of course, indicates increase in elasticity. The increase in elastic property can be interpreted by the fact that the loading of MA- $g-\mathrm{PE}$ in LLDPE/20A composites enhances the dispersion of clay in LLDPE melts. Wang et al. ${ }^{10}$ reported that the MA- $g$-PE/20A composites representing good interacting filler system show higher elastic properties

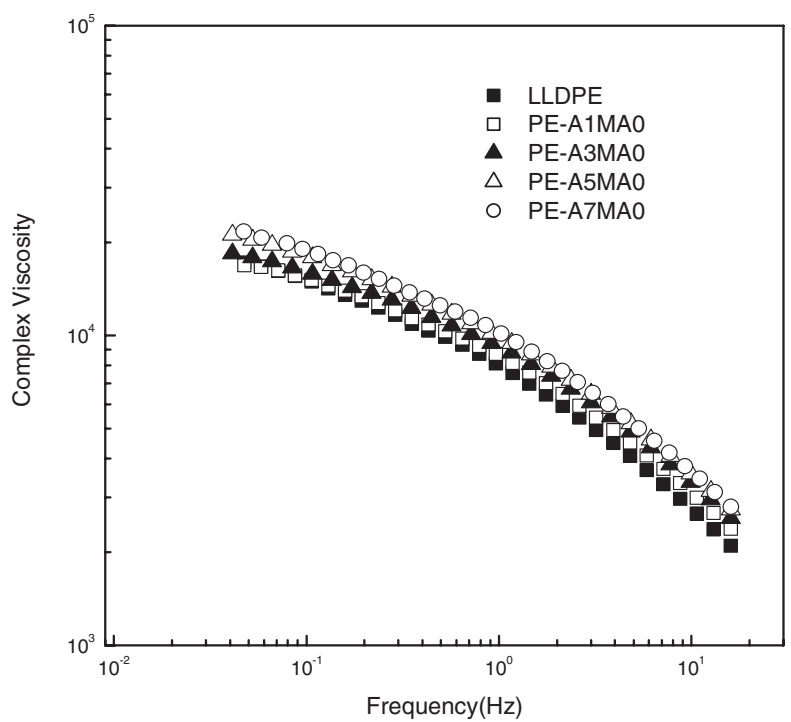

(a)

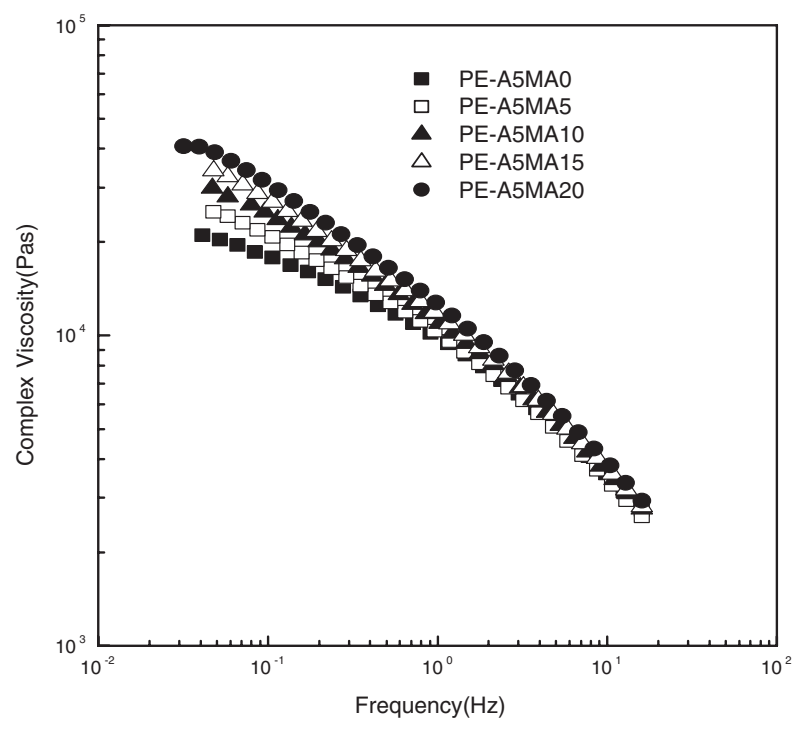

(b)

Figure 7. Complex viscosity of LLDPE/20A composite before (a) and after (b) loading MA-g-PE.

Table II. Viscosity ratios of the LLDPE/20A composites

\begin{tabular}{cc}
\hline Sample & Viscosity ratios \\
\hline PE-A1MA0 & 5.65 \\
PE-A3MA0 & 5.67 \\
PE-A5MA0 & 6.15 \\
PE-A7MA0 & 6.03 \\
PE-A5MA5 & 7.58 \\
PE-A5MA10 & 8.27 \\
PE-A5MA15 & 9.50 \\
PE-A5MA20 & 10.20 \\
\hline
\end{tabular}

${ }^{\mathrm{a}}$ Viscosity ratio $=\eta_{0.4 \mathrm{~Hz}} / \eta_{10 \mathrm{~Hz}}$.

than those of the MA- $g-\mathrm{PE} / \mathrm{SiO}_{2}$ composites.

A simple technique has been described to quantify changes in elastic property. ${ }^{15,27}$ The procedure in- 


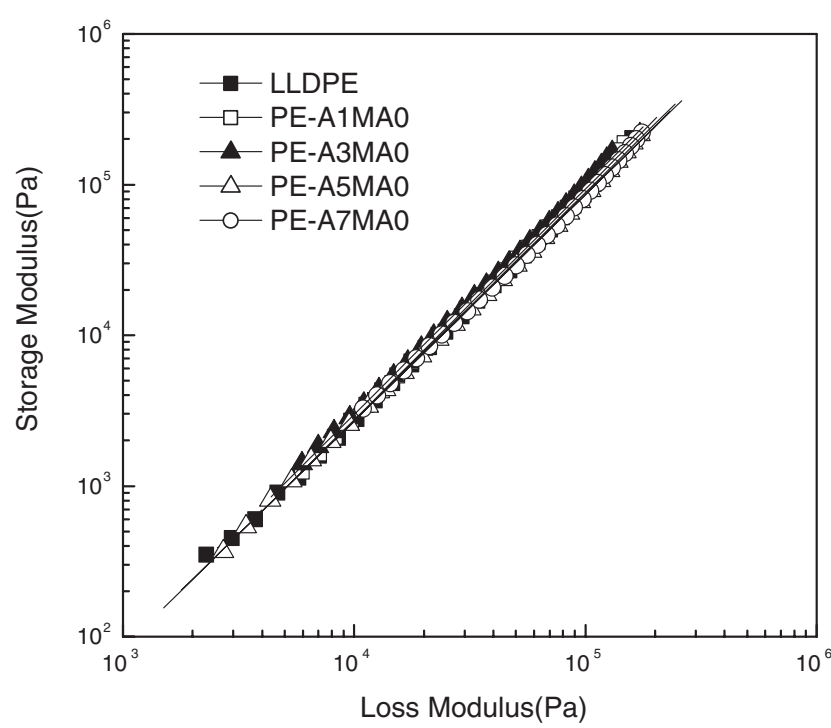

(a)

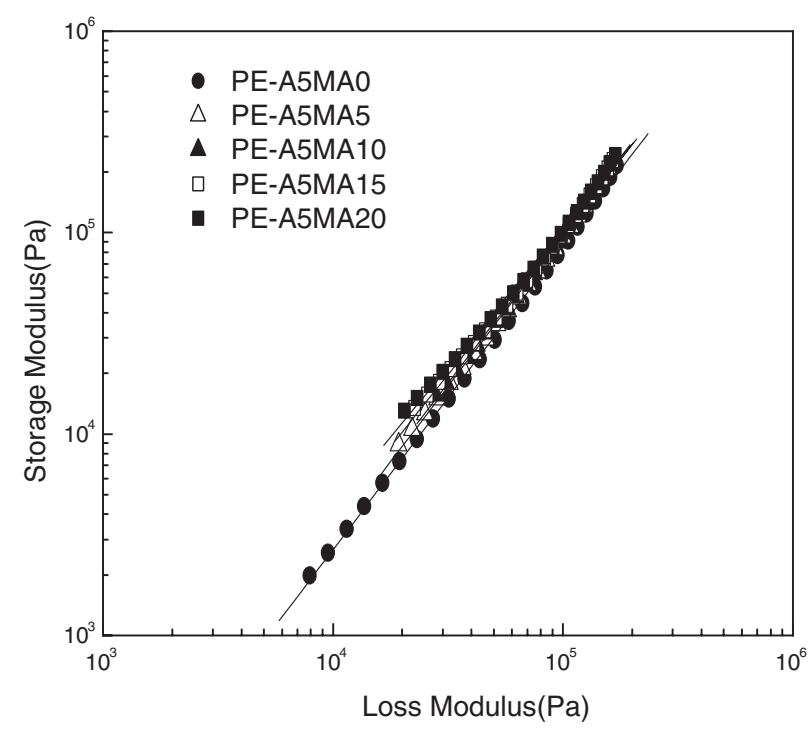

(b)

Figure 8. Plots of $\log G^{\prime}$ against $\log G^{\prime \prime}$ for LLDPE/20A composite before (a) and after (b) loading MA- $g$-PE. Solid lines indicate linear regression.

volves extrapolating plots of $\log G^{\prime}$ against $\log G^{\prime \prime}$ to low $G^{\prime \prime}$. The following measure, called ER, is extracted from $G^{\prime} v s . G^{\prime \prime}$ data: $\mathrm{ER}=C_{1} G^{\prime}$ at $G_{\text {ref }}^{\prime \prime}$ is selected to be a low modulus (corresponding to low frequencies) and $C_{1}$ is a normalization constant. ER can be considered as an elasticity index normalized to remove the effects of molecular weight. For polyolefin melts, good results have been obtained with $G_{\text {ref }}^{\prime \prime}=5000 \mathrm{~Pa}$ and $C_{1}=1.781 \times 10^{-3} \cdot G^{\prime}$ at $G^{\prime \prime}=$ 5000 was obtained using the linear regression since a $\log -\log$ plot of $G^{\prime} v s$. $G^{\prime \prime}$ is very nearly linear in that region (see solid line of Figure $8 \mathrm{~b}$ ). The slopes of linear regression and ER values are summarized in Table III. The composites with MA- $g$-PE show higher ER values than that of PE-A5MA0. High ER indicates
Table III. Slopes, $G^{\prime}$ and ER values of the LLDPE/20A composites

\begin{tabular}{cccc}
\hline Sample & Slopes $^{\mathrm{a}}$ & $G^{\prime}$ at $G^{\prime \prime}=5,000 \mathrm{~Pa}$ & $\mathrm{ER}$ \\
\hline PE-A1MA0 & 1.53 & 953 & 1.70 \\
PE-A3MA0 & 1.52 & 1,042 & 1.85 \\
PE-A5MA0 & 1.51 & 955 & 1.70 \\
PE-A7MA0 & 1.50 & 950 & 1.70 \\
PE-A5MA5 & 1.49 & 1,078 & 1.92 \\
PE-A5MA10 & 1.47 & 1,136 & 2.02 \\
PE-A5MA15 & 1.42 & 1,419 & 2.53 \\
PE-A5MA20 & 1.38 & 1,663 & 2.96 \\
\hline
\end{tabular}

${ }^{\text {a }}$ Slopes calculated by linear regression of plot $\log G^{\prime}$ against $\log G^{\prime \prime}$.

high elasticity. The increase in ER can be interpreted by the fact that the loading of MA- $g$-PE in LLDPE/ $20 \mathrm{~A}$ composites enhances the dispersion of $20 \mathrm{~A}$ in LLDPE melts within limited residence time in the mixer.

A principal factor in extrusion application of LLDPE is the surface smoothness of extrudate. In case of LLDPE, fine-scale surface distortion (shark-skin) usually occurs before wavy melt fracture.

Examination of surface morphology of extrudates for LLDPE/20A composites and after loading MA$g$-PE was carried out to evaluate the influence of the maleated modfication on melt fracture. Figure 9 shows SEM photos of extrudates for PE-A5MA0 and PE-A5MA15 as a function of shear rate. The fine scale surface distortion (sharkskin) occurs in both samples. In case of the PE-A5MA15 composite, the critical shear rate in wavy melt fractures, however, shifted toward higher value compared to the composites without MA- $g$-PE. The wavy melt fracture occurred at $8720 \mathrm{~s}^{-1}$ for the original LLDPE/20A composite but occurred at $10500 \mathrm{~s}^{-1}$ for LLDPE/20A composites having $15 \mathrm{wt} \% \mathrm{MA}-g$-PE.

Extrudate distortions are identified as irregular dimensional change can be explained by several causes including an inhomogeneous elastic response of the melt to flow fields. ${ }^{11,12}$ For linear polyethylenes such as LLDPE and high density polyethylene (HDPE), an increasing in elasticity is one of the dominating factors delaying melt fracture. Venet and Vergnes ${ }^{12}$ reported that the increase in elasticity tends to show a high shear thinning tendency and reduce the aptitude to melt fracture by increasing the tensile resistance during the extrusion of LLDPE. Since the maleated LLDPE/20A composite has a high elastic property as a result of physical jamming of the clay able to resist elongational stress when leaving the die, the MA$g$-PE modified LLDPE/clay composite could be less sensitive to melt fracture.

To clarify whether it is the effect of dispersion of 

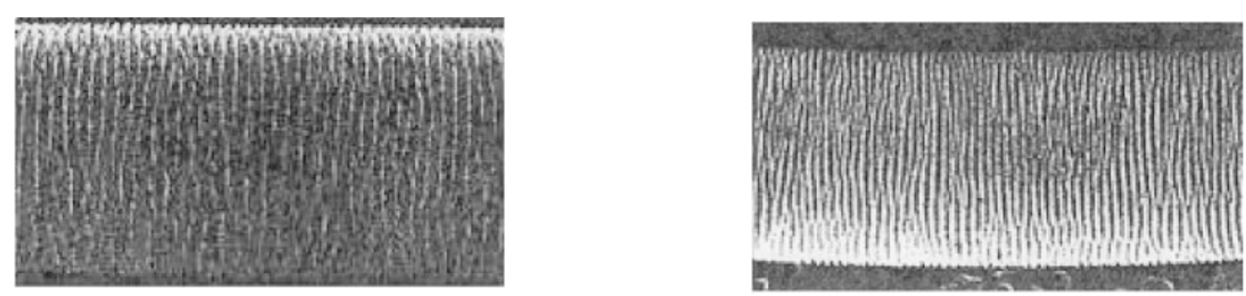

$6980 \mathrm{sec}^{-1}$
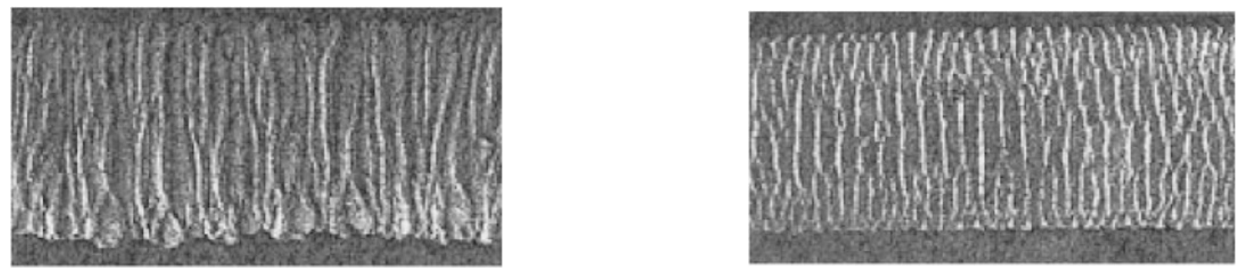

$8720 \sec ^{-1}$
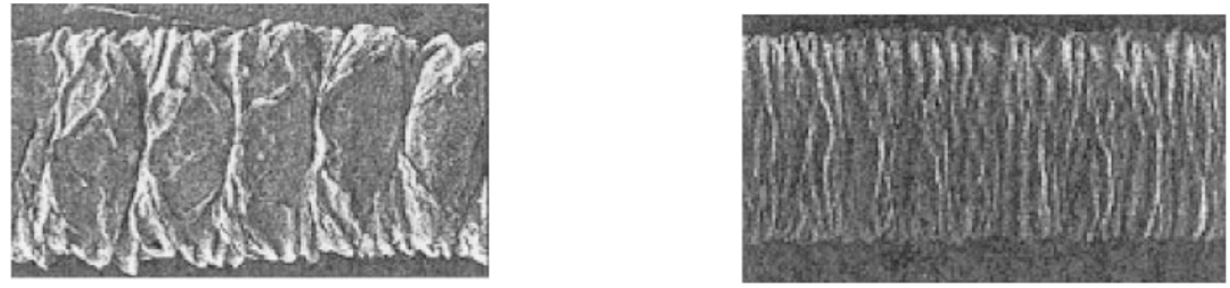

$10500 \mathrm{sec}^{-1}$

(a)

(b)

Figure 9. SEM photos for the extrudates of LLDPE/20A composite before (a) and after (b) loading $15 \mathrm{wt} \%$ MA- $g$-PE.

clay or that of presence of MA- $g$-PE, the same procedure was also applied to the blend with $15 \mathrm{wt} \%$ MA$g$-PE in the $85 \mathrm{wt} \%$ LLDPE resin. There was no detectable change in melt fracture even though data are not present here.

\section{CONCLUSIONS}

The original basal reflection peak of $20 \mathrm{~A}$ disappeared above a certain concentration of MA- $g$-PE, which is about $15 \mathrm{wt} \%$. This fact reveals that clays are exfoliated and dispersed homogeneously in the LLDPE/20A nanocomposites above $15 \mathrm{wt} \%$ of MA$g$-PE. The effects of maleated modification on the rheological properties of LLDPE/20A nanocomposites were examined by varying MA- $g$-PE concentration. As MA-g-PE concentration increased, the
LLDPE/20A composites showed an increase in complex viscosity, shear sensitivity and elastic property. The increase in elastic property can be interpreted by the fact that the loading of MA- $g$-PE in LLDPE/ 20A composites enhances the dispersion of clay in LLDPE melts. After MA- $g$-PE modifying, the LLDPE/20A nanocomposites exhibited a delay in the onset of melt fracture upon extrusion.

Acknowledgment. This work was supported by grant No. R01-2002-000-00290-0 from the Basic Research Program of the Korean Science \& Engineering Foundation.

\section{REFERENCES}

1. L. L. Beecroft and C. K. Ober, Chem. Mater., 9, 1302 
(1997).

2. R. Gangopadhyay and A. De, Chem. Mater., 12, 608 (2000).

3. Y. K. Kim, Y. S. Choi, K. H. Wang, and I. J. Chung, Chem. Mater., 14, 4990 (2002).

4. Y. Kojima, A. Usuki, M. Kawasumi, Y. Fukushima, A. Okada, T. Kurauchi, and O. Kamigaito, J. Mater. Res., 8, 1185 (1993).

5. R. Limary, S. Swinnea, and P. F. Green, Macromolecules, 33, 5227 (2000).

6. L. Zheng, R. J. Farris, and E. B. Coughlin, Macromolecules, 34, 8034 (2001).

7. P. H. Nam, P. Maiti, M. Okamoto, T. Kotaka, N. Hasegawa, and A. Usuki, Polymer, 42, 9633 (2001).

8. L. Priya and J. P. Jog, J. Polym. Sci., Polym. Phys. Ed., 41, 31 (2003).

9. A. Lele, M. Mackley, G. Galgali, and C. Ramesh, J. Rheol., 46, 1091 (2002).

10. K. H. Wang, M. H. Choi, C. K. Koo, Y. S. Choi, and I. J. Chung, Polymer, 42, 9819 (2001).

11. F. N. Cogswell, J. Non-Newtonian Fluid Mech., 2, 37 (1977).

12. C. Venet and B. Vergnes, J. Rheol., 41, 873 (1997).

13. S. Q. Wange and P. A. Drda, Macromolecules, 29, 2627 (1997).
14. M. V. Prooyen, T. Vremner, and A. Rudin, Polym. Eng. Sci., 34, 570 (1994).

15. R. Shroff, A. Prasad, and C. Lee, J. Polym. Sci., Part B: Polym. Phys., 34, 2317 (1996).

16. T. Bremner and A. Rudin, J. Appl. Polym. Sci., 57, 271 (1995).

17. S. T. Milner, J. Rheol., 40, 303 (1996).

18. N. Furuichi, Y. Kurokawa, K. Fujita, A. Oya, H. Yasuad, and M. Kiso, J. Mater. Sci., 31, 4307 (1996).

19. J. Heinemann, R. Thomann, and R. Mulhaupt, Macromol. Rapid Commun., 20, 423 (1999).

20. Y. Kurokawa, H. Yasuda, and A. Oya, J. Mater. Sci., 35, 1045 (2000).

21. M. Kawasumi, N. Hasegawa, M. Kato, A. Usuki, and A. Okada, J. Appl. Polym. Sci., 67, 87 (1998).

22. X. Liu and Q. Wu, Polymer, 42, 10013 (2001).

23. J. Li, C. Zhou, and W. Gang, Polym. Test., 22, 217 (2003).

24. F. A. Bovey and F. H. Winslow, "Macromolecules," Academic Press, New York, N.Y., 1979, p 214.

25. M. Sikka, L. N. Cerini, S. S. Ghosh, and K. I. Winey, J. Polym. Sci., Part B: Polym. Phys., 34, 1443 (1996).

26. R. A. Vaia and E. P. Giannelis, Macromolecules, 30, 8000 (1997).

27. Y. C. Kim and K. S. Yang, Polym. J., 31, 579 (1999). 